\author{
Н.В. Лосева, И.В. Ярославцева
}

\title{
ЭМОЦИОНАЛЬНЫЕ ПЕРЕЖИВАНИЯ В СТРУКТУРЕ ЛИЧНОСТИ ЖЕНЩИН С НАРУШЕНИЕМ РЕПРОДУКТИВНОЙ ФУНКЦИИ
}

\begin{abstract}
Аннотация. В статье обобщены и систематизированы научные представления о феномене эмоциональных переживаний женщин с нарушением репродуктивной функции. Определено влияние эмоциональных переживаний на репродуктивную функцию женщин. Представлены результаты эмпирического исследования эмоциональных переживаний пятидесяти женщин с нарушением репродуктивной функции различного характера: нарушения гормонального происхождения, нарушения функции маточных труб, невынашивание беременности, нарушение внутриутробного развития ребёнка, гинекологические заболевания соматического характера (эндометриоз, миомы, кисты), не гинекологические заболевания соматического характера, влияющие на успешность репродуктивной функции.

Показано, что для женщин с нарушением репродуктивной функции характерны такие эмоциональные переживания как высокий уровень личностной и ситуативной тревожности, склонность к депрессии, высокий уровень фрустрированности, тревожный и амбивалентный стиль переживания возможной беременности и будущего материнства. По результатам исследования рассмотрена структура личностных проявлений женщин с нарушением репродуктивной функции, в которой эмоциональные переживания выступают центральным образованием. Эти переживания являются базовыми и во многом определяют качество жизни женщин и результаты лечебного и реабилитационного процесса. Учёт специфики эмоциональных переживаний будет способствовать более качественной психологической помощи женщинам с нарушение репродуктивной функции.

Ключевые слова: психология, переживание, нарушение репродуктивной функции, структура личности, бесплодие, стресс, стиль переживания беременности, депрессия, фрустрированность, тревожность.
\end{abstract}

H ачиная с 90-х годов XX века, в науке о человеке активно обсуждаются проблемы психологических составляющих репродуктивного здоровья. Так в работах Дж. Шенкер, Г.Г. Филипповой, Е. Шейнер, показано, что выраженная тревожность у женщин приостанавливает работу репродуктивной системы, что может спровоцировать формирование её патологии и повлечь развитие других негативных психологических явлений, как реакций на нарушение.

Наиболее выраженными негативными психологическими проявлениями нарушений репродуктивной функции по данным, В.Д. Менделевича, Э.В. Макаричевой, Т.А. Федорова и др. являются психоэмоциональное напряжение, тревожность и депрессивные реакции, в совокупности представляющие эмоциональные переживания.
В общепринятом же понимании переживание рассматривается как глубокое, тяжёлое душевное состояние, вызванное сильными ощущениями, впечатлениями. В настоящее время существует несколько теоретических подходов к проблеме переживаний человека. В первом подходе, в традициях зарубежной и отечественной психологии, определение места, роли, положения переживания в психическом мире человека связано с сознанием. Так, Л.С. Выготский определял переживание подвижной единицей сознания; С.Л. Рубинштейн рассматривал переживание человека соотносительно с актуальным для него знанием; А.Н. Леонтьев, при анализе проблем личностного смысла бытия, предавал особое значение сигнальной функции переживаний.

Переживание в трудах К.К. Платонова рассматривается как эмоциональное составляющее со- 
знания. По его мнению, переживание не включает образа отражаемого, а состоит в форме удовольствия или неудовольствия (страдания), напряжения или разрешения, возбуждения или успокоения. Такое же понимание феномена переживания просматривается в работах Л.М. Веккера. Он считает, что переживание является непосредственным отражением самим субъектом собственных состояний, а не отражением свойств и соотношений внешних эмоциогенных объектов ${ }^{1}$.

Помимо разнообразных дефиниций «переживание» в современной отечественной психологии существует некоторая недифференцированность понятий «переживание», «эмоция» и «психическое состояние». П.В. Симонов, Б.И. Додонов, Е.П. Ильин, А.Ф. Корниенко и др. рассматривают «переживание» и «эмоция» как явление одного спектра психических состояний. А.С. Шаров, Ф.Е. Василюк и др. относят переживание к эмоциям с выраженной рефлексивностью. В.К. Вилюнас говорит, что переживание - это эмоциональное выражение осознанного отношения человека к миру.

П.К. Анохин переживания обозначает как механизм адаптации человека к окружающей среде. Он считает, что самой важной чертой эмоционального состояния является его интегративность. Эмоции охватывая практически весь организм, производя моментальное объединение в одно целое всех его функций. По его мнению, именно эмоции непрерывно поддерживают организм в состоянии оптимального функционирования. Психофизиологическая функция эмоциональных переживаний состоит в том, что они обеспечивают наши реакции в ответ на значимые внешние и внутренние воздействия дополнительной энергии ${ }^{2}$.

На основе подхода А.Н. Леонтьева, П.И. Анохина были сформированы взгляды Ф.Е. Василюка, который определяет переживание как любое испытываемое субъектом эмоционально окрашенное состояние и явление действительности, непосредственно представленное в его сознании и выступающее для него как событие его собственной жизни ${ }^{3}$.

Переживание как деятельность реализуется внешними и внутренними действиями, и они

\footnotetext{
1 Ильин Е.П. Эмоции и чувства. СПб.: Питер, 2007. С. 784.

2 Анохин П.К. Эмоции // Большая медицинская энциклопедия. 2-е изд. М., 1964. Т. 35. С. 339-367.

3 Василюк Ф.Е. Психология переживания: анализ преодоления критических ситуаций. М.: Изд-во МГУ, 1984. 200 с.
}

неотделимы от физиологических изменений организма. В зависимости от глубины и интенсивности воздействия на человека эмоциональные переживания могут быть как благотворные, так и разрушительные. Так следы отрицательных эмоциональных переживаний, повторных и длительных, накапливаясь и суммируясь, оказывают иммуносупрессивное действие, что может разрушать защитную функцию барьерной системы и вести к соматическим расстройствам. Наиболее уязвимой системой организма человека является репродуктивная сфера.

Репродуктивная сфера - это совокупность физиологических и психологических механизмов, решающих задачи зачатия, вынашивания, рождения, воспитания ребёнка ${ }^{4}$. С психологической позиции репродуктивная функция детерминирована образованием материнской доминанты. Её актуализация запускает процесс сопряженного функционирования физиологических и психических функций репродукции человека. Основу репродуктивной функции составляет функциональная система, выступающая, по мнению П.К. Анохина, психофизиологическим механизмом, который организует всю жизнедеятельность женщин в необходимом направлении 5 . Функциональной система, на взгляд автора, является «временным органом», которая регулируется, по мнению А.А. Ухтомского, посредством ведущей доминанты ${ }^{6}$.

В науке выделено несколько особенностей репродуктивной сферы человека. Первая отличительная особенность заключается в том, что она не является сферой жизнедеятельности и направлена на реализацию не индивидных, а видовых потребностей. Вторая особенность репродуктивной сферы - это половая и родительская составляющие, имеющие общие физиологические механизмы, но различные психические компоненты. Так, Г.Г. Филиппова отмечает, что половое поведение направлено на реализацию индивидных потребностей, а родительское - видовых потребностей человека. Регуляция половой и родительской составляющих репродуктивной функции осуществляется доминантой материнства, которая реализуется

\footnotetext{
4 Филиппова Г.Г. Психология материнства: учеб. пособие. М.: Изд-во ин-та психотерапии, 2002. 240 с.

5 Анохин П.К. Узловые вопросы теории функциональных систем. М.: Наука, 1980. С. 197.

6 Ухтомский А.А. Доминанта. М.; Л.: Наука, 1966. С. 273.
} 


\section{Спектр эмоциональных переживаний}

посредством актуализации субдоминант полового поведения, зачатия, вынашивания, рождения и воспитания ребёнка.

На взгляд Г.Г. Филипповой, нарушение репродуктивной функции связано с расстройством механизмов субдоминант. К таким механизмам можно отнести механизм родительской психологической готовность к выполнению репродуктивной функции и механизм сверхценного образования «ребёнка». Сверхценное образование «ребёнка», например, в ряде неудач деторождения, сопровождается интенсивными эмоциональными переживаниями, что влечёт торможение сопряженных систем и усиление патологических доминант.

Если реализация репродуктивной функции вступает в конфликт с удовлетворением индивидных потребностей, то возникают основания для формирования психосоматических механизмов психологической защиты, мишенью которых становится сама репродуктивная система. Имеющиеся в современной психологии материнства данные свидетельствуют о том, что во всех случаях нарушения репродуктивной функции сопровождаются искажением психологической составляющей материнской сферы: отсутствием положительного образа будущего материнства; неадекватной ценностью ребенка и материнства; нарушением полоролевой идентичности; доминированием направленности на сохранение своих ресурсов, опекой по отношению к себе, реализацией индивидных потребностей в достижении, самореализации и т.д., в результате фрустрации последних при переходе к материнству.

Реакция на нарушение репродуктивной функции, по мнению Диноры Пайнс, Э.В. Кришталь, более интенсивна у женщин. Выраженные эмоциональные переживания проявляются на второйтретий год бесплодия, далее происходит адаптация к расстройству и снижение эмоционального неблагополучия. Т.А. Федорова проводит анализ эмоциональной и сексуальной сферы женщин с «необъяснимым» бесплодием и показывает, что первичным нарушением является именно бесплодие. Оно подчёркивает, что у большинства женщин отмечается эмоциональная лабильность, чувство неполноценности, одиночества, изменение эмоционального состояния в дни, предшествующие менструации («синдром ожидания беременности»). Бесплодие приводило к нарушению межперсональных отношений, ощущению нестабильности семейного положения, среди обследованных жен- щин повторные браки отмечались в пять раз чаще, чем у здоровых женщин.

A.T. Терешин, оценивая психоэмоциональное состояние женщин с бесплодием, вызванным гипоталамо-гипофизарной дисфункцией, практически у всех обследованных выявил нарушение эмоционального состояния, а у половины женщин в этиологии бесплодия проследил хронические и острые стрессовые ситуации. У большей половины женщин выявлены многофакторные психотравмы, которые продолжались от одного года до десяти лет. Большинство женщин (69\%) демонстрировали повышенный уровень тревожности.

D.X. Rosenfeld и E. Mitchell, исследуя эмоциональное реагирование на бесплодие, выделили несколько этапов в его развитии: удивление, горе, злость, изоляция, отрицание и согласие. Р. Кочюнас, используя модель Кублера Росса, рассмотрел эмоциональные переживания при описании процесса скорби через чередование следующих стадий: отрицание, озлобленность, компромисс, депрессия, адаптация7. Такие же чувства может испытывать женщина, сделавшая аборт или потеряв ребенка при беременности.

И.Ю. Свяцкевич, опираясь на исследования российских и зарубежных авторов, описывает психологические последствия бесплодия: снижение самооценки, самоуважения личности; изменения в супружеских отношениях и удовлетворенности браком; изменения в сексуальной сфере; синдром ожидания беременности.

В исследованиях В.Д. Менделевича и Э.В. Макаричевой в преморбиде у большинства женщин с необъяснимым бесплодием выделены слабая половая конституция и черты психического инфантилизма. С помощью теста MМРI В.Д. Менделевич и Э.В. Макаричева выявили определенный личностный профиль бесплодных женщин, в котором ярко проявились склонность к депрессивным реакциям, конфликтность, эмоциональная неустойчивость, тревожность с выраженным стремлением нравиться всем окружающим, неуверенность в себе, зависимость самооценки от мнения окружающих ${ }^{8}$. А.В. Колчин и Н.А. Богдан показали, что у

\footnotetext{
Кочунас Р. Психологическое консультирование и групповая психотерапия: учебное пособие. М.: Академический проект: Трикста, 2008. С. 64.

8 Макаричева Э.В., Менделевич В.Д. Психический инфантилизм и необъяснимое бесплодие // Социальная и клиническая психиатрия. 1996. № 3. С. 20-22.
} 
женщин с нарушением репродуктивного здоровья отмечается неудовлетворённость собой, снижение самооценки, незрелость с проявлениями недоверия к миру. Отсутствие фертильности они связывают с базовым недоверием окружающему миру, выступающим проявлением личностной незрелости. Недоверие окружающим проявляется в таких особенностях личности, как повышенное желание контролировать ситуацию вокруг, непринятие нового, психологическая негибкость, чрезмерная приверженность четкому планированию. Бесплодные женщины неуверенны не только в окружающих, своем партнере, но и в себе. В качестве отличительной особенности бесплодных женщин авторы выделяют заниженную самооценку или компенсированную заниженную самооценку, которые могут приводит к стремлению к перфекционизму.

Н.А. Богдан указывает, что у женщин с нарушенной фертильностью имеется внутренний конфликт в психологическом принятии своего пола, который часто формируется вследствие конфликтных отношений с родителями в детстве. Как следствие они асексуальны, что проявляется в повышенной ценности карьеры, поведении, свойственном противоположному полу - лидерстве, принятии на себя высокой ответственности, волевом характере 9 .

Исследователями отмечается, что бесплодные женщины часто имеют трудности и психотравмы детского возраста, а так же различные страхи в виде страхов потери привлекательности, карьеры, внимания мужа, физической боли, родов, страх утраты независимости, и другие. Многие женщины воспитывались в многодетной семье или в детском учреждении. О.С. Карымова показала, что большинство бесплодных женщин эмоционально неустойчивы, при этом их отличает конфликт между разнонаправленными стремлениями: эгоизмом и альтруизмом, агрессивностью и стремлением нравиться, обособленностью и принадлежностью группе. При этом для них характерна маскулинность, независимость, стремление к эмансипации, самодостаточность, они склонны к психосоматическим расстройствам. Многие женщины прояв-

\footnotetext{
9 Богдан Н.А. Психологические проблемы, сопровождающие проблему бесплодия и возможности оказания психологической помощи в процессе его лечения методом ЭКО // Перинатальная психология и медицина, психосоматические расстройства в акушерстве, гинекологии, педиатрии и терапии: Матер. Всерос. конф. Иваново, 2001. С. 98-101.
}

ляют властность, независимость, обособленность в группе. В некоторой степени они самодовольны, упорны, подозрительны к окружающим. Женщинам свойственно прислушиваться к мнению окружающих и порой зависеть от их мнения.

В перинатальной психологии принято выделять две группы женщин, имеющих осложнения зачатия и течения беременности (А и Б) ${ }^{10}$. В группу А входят женщины, имеющие нарушение репродуктивной функции до беременности в основном гормонального происхождения, бесплодие или трудности зачатия, угрозу прерывания беременности и невынашивания, нарушение внутриутробного развития ребенка с минимальным риском для своего здоровья. К группе Б отнесены женщины с гинекологическими заболеваниями соматического характера и негинекологическими соматическими проблемами, влияющими на успешность репродуктивной функции и одновременно угрожающими здоровью женщины.

В исследованиях показаны личностные отличия женщин этих групп. Для женщин из группы А характерны следующие психологические особенности: эмоциональная неустойчивость, склонность к гиперстеническому реагированию, что проявляется повышенной раздражительности, эмоциональной лабильности, высокой возбудимости и склонности к вербальной агрессии. Характерно понижение работоспособности за счет первичной слабости активного внимания: рассеянность и несобранность, невозможность «включиться»в работу и сосредоточиться на выполняемом деле. Проявляется склонность к перепадам настроения; болезненному отношению к неудачам с накоплением отрицательных эмоций и их взрывчатым выплеском; к формированию сверхценных идей репродуктивной функции и беременности. Наблюдается искажение женской идентичности: усиление маскулинных качеств и ослабление женственности, отвержение собственной женственности; снижение уровня социальной адаптации, отсутствие гибкости во взаимодействии; конфликтные отношения с матерью, иногда выражающиеся в некритичной идеализации и недифференцированном представлении об отношениях с ней; неудовлетворенность собой, завышенная самооценка;

\footnotetext{
10 Абрамченко В.В. Психосоматическое акушерство. СПб.: Сотис, 2001. С. 320; Макаричева Э.В., Менделевич В.Д. Психический инфантилизм и необъяснимое бесплодие // Социальная и клиническая психиатрия. 1996. № 3. С. 20-22.
} 


\section{Спектр эмоциональных переживаний}

неудовлетворенность отношением к себе других, претензии к ним; защитное декларирование ценности материнства; пониженная ценность ребенка; повышенная тревожность с преимущественно выраженной эмоциональной составляющей; возможно недостаточное осознание болезни, эйфория; гетероагрессия, чаще подавленная.

У женщин группы Б диагностированы такие психологические особенности как эмоциональная неустойчивость, склонность к гипостеническому реагированию, что проявляется в постоянной вялости, физической и психической слабости, пассивности, снижении настроения, отсутствии интересов, чувстве грусти и какой-то неопределенной тревожности. Женщины склонны к депрессиям, зависимы от окружающих. У них, в отличии от женщин группы A, наблюдается ненарушенная женская идентичность; тревожные и зависимые, симбиотические отношения с матерью; неуверенность в себе, заниженная самооценка, чувство вины; доверие, некритичность по отношению к другим, неуверенность в своей материнской компетентности, сверхответственность, повышенная или наоборот пониженная ценность ребенка. Помимо этого женщин беспокоит повышенная тревожность с преимущественно выраженной соматической (функциональной) составляющей; невротические реакции по типу «бегство в болезнь»; чаще подавленная аутоагрессия, риск суицида.

Выявленные особенности свидетельствуют о том, что женщины обеих групп имеют, во-первых, выраженный внутренний конфликт в материнской сфере, во-вторых, инфантильный способ разрешения конфликтной ситуации по типу соматизации и нарушения психологической адаптации. В-третьих, различия по форме конфликта в материнской сфере, адаптационным механизмам и формам соматизации конфликтной ситуации.

Г.Г. Филиппова дополняет и расширяет информацию о различиях, свойственных женщинам из групп А и Б. Она полагает, что для женщин группы А характерны непринятие своей женственности и подавленная гетероагрессия, неготовность к материнству в форме «конфликтность». Им свойственны защитная декларация тревоги за ребенка и сверхценность материнства, что выражается в негативном невербальном и позитивном вербальном образах своего ребенка и себя как матери. Для женщин характерны принятие своей женственности и подавленная аутоагрессия, а также неготовность к материнству в форме «тревожность». Женщины этой группы отличаются реальной декларацией тревоги за ребёнка и сверхценности материнства в сочетании с тревогой по поводу своей несостоятельности, что выражается в позитивном невербальном и недифференцированном или негативном вербальном образах своего ребенка и себя как матери ${ }^{11}$.

Как показывает анализ проведённых исследований, при наличии широкого спектра личностных проявлений центральным образованием личности женщин с нарушением репродуктивной функции являются эмоциональные переживания. Для подтверждения этого положения, нами исследовано пятьдесят женщин с нарушением репродуктивной функции. В исследовании применялись следующие методики: методика диагностики ситуативной и личностной тревожности Ч.Д. Спилбергера, в адаптации Ю.Л. Ханина; методика диагностики уровня социальной фрустрированности Л.И. Вассермана (в модификации В.В. Бойко); шкала депрессии (Т.И. Балашова, О.П. Елисеева) предназначенная для диагностики наличия и степени выраженности депрессии; проективная рисуночная методика «Я и мой будущий ребенок» (Г.Г. Филиппова) для выявления эмоциональной готовности женщины к материнству.

В ходе исследования было выявлено, что для женщин с нарушением репродуктивной функции характерны следующие эмоциональные переживания: высокий уровень личностной и ситуативной тревожности, склонность к депрессии, высокий уровень фрустрированности, тревожный и амбивалентный стиль переживания возможной беременности и будущего материнства. Выявленные нами ведущие мотивы рождения ребёнка были различны, основными мотивами выступили следующие: мотив «ребёнок как объект любви» и мотив «соответствие социальным ожиданиям».

Высокие показатели личностной тревожности, свидетельствующие о склонности человека к восприятию жизнедеятельности в различных ситуациях, позволяют заключить, что у женщин с нарушением репродуктивной функции возможны нарушения адекватности проявлений эмоций. Следствием высокой тревожности является высокий уровень напряжения и фрустрированности женщин. Большинство женщин, в связи с невозможностью удовлетворить свои репродуктивные

11 Филиппова Г.Г. Психология материнства: учеб. пособие. М.: Изд-во ин-та психотерапии, 2002. С. 240; Филиппова Г.Г. Психология материнства. Концептуальная модель. М.: Ин-т Молодежи, 1999. С. 286. 
потребности, испытывает переживание неудачи, разочарования, тревоги, раздражительности. В беседах женщины отмечают, что им трудно общаться с окружающими, например, с имеющими детей, беременными женщинами и детьми. В рабочем коллективе они стараются держаться обособленно, не рассказывать о своих проблемах с деторождением. Так же женщины отмечают проблемы в отношениях с родственниками и близкими людьми. Большинство из них переживают свою ущербность, испытывают страх оценки или неуспеха, предъявляют чрезмерные требования к себе и окружающим, переживают чувство ненужности в коллективе или в кругу друзей и близких ${ }^{12}$.

Можно заключить, что в структуре личностных проявлений женщин с нарушением репро- дуктивной функции эмоциональные переживания выступают центральным образованием личности. Эти переживания являются базовыми, во многом определяют качество жизни женщин с нарушение репродуктивной функции и результаты их лечения. Большинством исследователей признаётся влияние психологических составляющих, обусловленных бесплодием, на результаты лечения ${ }^{13}$. Однако сегодня недостаточно работ, посвященных психологическим проявлениям и последствиям нарушений репродуктивной функции, разработки путей психологической помощи таким женщинам. Без разработки этих проблем невозможно достичь высоких результатов лечения женщин с нарушением репродуктивной функции.

\section{Список литературы:}

1. Абрамченко В.В. Психосоматическое акушерство. СПб.: Сотис, 2001.

2. Анохин П.К. Узловые вопросы теории функциональных систем. М.: Наука, 1980.

3. Анохин П.К. Эмоции // Большая медицинская энциклопедия. 2-е изд. М., 1964. Т. 35. С. 339-367.

4. Березина Т.Н. Радость и удовольствие как базовые эмоции // Психология и психотехника. 2012 . № 7. C. $40-47$.

5. Блох М.Е., Аверин В.А., Корнев А.Н. Влияние мотивации пациенток к использованию вспомогательных репродуктивных технологий на результативность этих методов // Рождение и жизнь: Материалы международной конференции по клинической психологии детства. СПб.: Изд-во СПбГПМА, 2010. С. 239-240.

6. Богдан Н.А. Психологические проблемы, сопровождающие проблему бесплодия и возможности оказания психологической помощи в процессе его лечения методом ЭКО // Перинатальная психология и медицина, психосоматические расстройства в акушерстве, гинекологии, педиатрии и терапии: Матер. Всерос. конф. Иваново, 2001. С. 98-101.

7. Брехман Г.И., Лапочкина Л.Н. Индивидуальные особенности женщин с физиологическим течением и угрозой невынашивания беременности в первом триместре беременности по данным MMPI // Журнал практического психолога. 1996. № 3. С. 29-32.

8. Вагнер В.А., Калягина Г.В. Сравнительная психология. М.: Институт практич. психологии, 1998.192 с.

9. Василюк Ф.Е. Психология переживания: анализ преодоления критических ситуаций. М.: Изд-во МГУ, 1984. 200 c.

10. Вилюнас В. Психология эмоций. М.: Изд-во МГУ, 1984. 303 с.

11. Добряков И.В. Перинатальная психология. СПб.: Питер, 2010. 272 с.

12 Лосева Н.В., Ярославцева И.В. Изменение эмоциональных переживаний у женщин с нарушением репродуктивной функции в процессе психологического консультирования // Проблемы теории и практики современной психологии: XII ежегод. Всерос. (с междунар. участием) науч.-практ. конф. студентов, аспирантов и молодых учёных, посвящ. 20-летию фак. психологии ИГУ: тез. докл. Иркутск: Изд-во ИГУ, 2013. C. $345-348$.
13 Блох М.Е. Влияние мотивации пациенток к использованию вспомогательных репродуктивных технологий на результативность этих методов // Рождение и жизнь: Материалы международной конференции по клинической психологии детства. СПб.: Изд. СПбГПМА, 2010. С. 239-240; Кулакова Е.В. Коррекция психоэмоциональных нарушений у пациенток с бесплодием в программе вспомогательных репродуктивных технологий. Автореф. дисс. ... канд. мед. наук. М., 2007. С. 27; Ланцбург М.Е. Роль психологической подготовки и поддержки в реализации родительских функций // Психологическая наука и образование. 2011. № 1. С. 15-18. 


\section{Спектр эмоциональных переживаний}

12. Идобаева О.А., Подольский А.И. Пути повышения психоэмоционального благополучия современных подростков // Психология и психотехника. 2010. № 6. С. 72-78.

13. Изард К. Психология эмоций. СПб.: Питер, 2003. 464 с.

14. Ильин Е.П. Эмоции и чувства. СПб.: Питер, 2007. 784 с.

15. Колчин А. Психологические аспекты репродукции человека // Проблемы репродукции. 1995. № 1. C. $12-13$.

16. Корнеенков С.С. Психологическое самоисследование и психотерапия личности в измененном состоянии сознания // NB: Психология и психотехника. 2013. № 1. С. 38-88. (URL: http://www.e-notabene.ru/ psp/article_105.html).

17. Кочунас Р. Психологическое консультирование и групповая психотерапия: учебное пособие. М.: Академический проект: Трикста, 2008. 464 с.

18. Крыжановский Г.Н. Детерминантные структуры в патологии нервной системы. М.: Медицина, 1980. $359 \mathrm{c}$.

19. Кулакова Е.В. Коррекция психоэмоциональных нарушений у пациенток с бесплодием в программе вспомогательных репродуктивных технологий. Автореф. дисс. ... канд. мед. наук. М., 2007.

20. Ланцбург М.Е. Роль психологической подготовки и поддержки в реализации родительских функций // Психологическая наука и образование. 2011. № 1. С. 15-18.

21. Леонтьев В.О. Классификация эмоций. Одесса: Изд-во Инновационно-ипотечного центра, 2002. $201 \mathrm{c.}$

22. Ломов Б.Ф. Системность в психологии. М.: Ин-т практич. психологии; Воронеж: МОДЭК, 1996. 384 с.

23. Лосева Н.В., Ярославцева И.В. Изменение эмоциональных переживаний у женщин с нарушением репродуктивной функции в процессе психологического консультирования // Проблемы теории и практики современной психологии: XII ежегод. Всерос. (с междунар. участием) науч.-практ. конф. студентов, аспирантов и молодых учёных, посвящ. 20-летию фак. психологии ИГУ: тез. докл. / редкол.: И.А. Конопак и др. Иркутск: Изд-во ИГУ, 2013. С. 345-348.

24. Макаричева Э.В., Менделевич В.Д. Психический инфантилизм и необъяснимое бесплодие // Социальная и клиническая психиатрия. 1996. № 3. С. 20-22.

25. Меньшикова А.А. Совладающее поведение беременных женщин с онкологическими заболеваниями // Психология и психотехника. 2011. № 10. С. 42-48.

26. Павлов И.П. Полное собрание сочинений: в 6-и т. Л.: Изд-во АН СССР, 1951. Т. 4. 452 с.

27. Рубинштейн С.Л. Основы общей психологии. СПб.: Питер, 2000. 528 с.

28. Симонов П.В. Теория отражения и психофизиология эмоций. М.: Центр, 1979. 189 с.

29. Ухтомский А.А. Доминанта. М.; Л.: Наука, 1966. 273 с.

30. Филиппова Г.Г. Психология материнства. Концептуальная модель. М.: Ин-т Молодежи, 1999. 286 с.

31. Филиппова Г.Г. Психология материнства: учеб. пособие. М.: Изд-во ин-та психотерапии, 2002. 240 с.

32. Яценко В.И. Влияние дефицита врожденных доминант личности на поведение человека // NB: Психология и психотехника. 2013. № 10. C. 1-39. (URL: http://www.e-notabene.ru/psp/article_10694.html).

33. Connolly, K.J. Edelmann, R. Cooke. L.D. and Robson, J. The impact of infertility on psychological functioning // Journal of psychosomatic Research. 1992; 36. P. 459-468.

34. Mendola, R., Tennen, H., Affleck, G., McCann, L. Fitzgerald, T. Appraisal and adaptation among women with impaired fertility // Cognitive Therapy and Research. 1990; 14. P. 59-93.

\section{References (transliteration):}

1. Abramchenko V.V. Psikhosomaticheskoe akusherstvo. SPb.: Sotis, 2001.

2. Anokhin P. K. Uzlovye voprosy teorii funktsional'nykh sistem. M.: Nauka, 1980.

3. Anokhin P.K. Emotsii // Bol'shaya meditsinskaya entsiklopediya. 2-e izd. M., 1964. T. 35. S. 339-367.

4. Berezina T.N. Radost' i udovol'stvie kak bazovye emotsii // Psikhologiya i psikhotekhnika. 2012. № 7. S. 4047.

5. Blokh M.E., Averin V.A., Kornev A.N. Vliyanie motivatsii patsientok k ispol'zovaniyu vspomogatel'nykh reproduktivnykh tekhnologii na rezul'tativnost' etikh metodov // Rozhdenie i zhizn': Materialy mezhdunarodnoi konferentsii po klinicheskoi psikhologii detstva. SPb.: Izd-vo SPbGPMA, 2010. S. 239-240. 


\section{Психология и психотехника 4(67) • 2014}

6. Bogdan N.A. Psikhologicheskie problemy, soprovozhdayushchie problemu besplodiya i vozmozhnosti okazaniya psikhologicheskoi pomoshchi v protsesse ego lecheniya metodom EKO // Perinatal'naya psikhologiya i meditsina, psikhosomaticheskie rasstroistva $\mathrm{v}$ akusherstve, ginekologii, pediatrii i terapii: Mater. Vseros. konf. Ivanovo, 2001. S. 98-101.

7. Brekhman G.I., Lapochkina L.N. Individual'nye osobennosti zhenshchin s fiziologicheskim techeniem i ugrozoi nevynashivaniya beremennosti $\mathrm{v}$ pervom trimestre beremennosti po dannym MMPI // Zhurnal prakticheskogo psikhologa. 1996. № 3. S. 29-32.

8. Vagner V.A., Kalyagina G.V. Sravnitel'naya psikhologiya. M.: Institut praktich. psikhologii, 1998. $192 \mathrm{s.}$

9. Vasilyuk F.E. Psikhologiya perezhivaniya: analiz preodoleniya kriticheskikh situatsii. M.: Izd-vo MGU, 1984. $200 \mathrm{~s}$.

10. Vilyunas V. Psikhologiya emotsii. M.: Izd-vo MGU, 1984. 303 s.

11. Dobryakov I.V. Perinatal'naya psikhologiya. SPb.: Piter, 2010. $272 \mathrm{s.}$

12. Izard K. Psikhologiya emotsii. SPb.: Piter, 2003. 464 s.

13. Idobaeva O.A., Podol'skii A.I. Puti povysheniya psikhoemotsional'nogo blagopoluchiya sovremennykh podrostkov // Psikhologiya i psikhotekhnika. 2010. № 6. S. 72-78.

14. Il'in E.P. Emotsii i chuvstva. SPb.: Piter, 2007. 784 s.

15. Kolchin A. Psikhologicheskie aspekty reproduktsii cheloveka // Problemy reproduktsii. 1995. № 1. S. 12-13.

16. Kochunas R. Psikhologicheskoe konsul'tirovanie i gruppovaya psikhoterapiya: uchebnoe posobie. M.: Akademicheskii proekt: Triksta, 2008. 464 s.

17. Korneenkov S.S. Psikhologicheskoe samoissledovanie i psikhoterapiya lichnosti v izmenennom sostoyanii soznaniya // NB: Psikhologiya i psikhotekhnika. 2013. № 1. S. 38-88. (URL: http://www.e-notabene.ru/psp/ article_105.html).

18. Kryzhanovskii G.N. Determinantnye struktury v patologii nervnoi sistemy. M.: Meditsina, 1980. 359 s.

19. Kulakova E.V. Korrektsiya psikhoemotsional'nykh narushenii u patsientok s besplodiem v programme vspomogatel'nykh reproduktivnykh tekhnologii. Avtoref. diss. ... kand. med. nauk. M., 2007.

20. Lantsburg M.E. Rol' psikhologicheskoi podgotovki i podderzhki v realizatsii roditel'skikh funktsii // Psikhologicheskaya nauka i obrazovanie. 2011. № 1. S. 15-18.

21. Leont'ev V.O. Klassifikatsiya emotsii. Odessa: Izd-vo Innovatsionno-ipotechnogo tsentra, 2002. $201 \mathrm{~s}$.

22. Lomov B.F. Sistemnost' v psikhologii. M.: In-t praktich. psikhologii; Voronezh: MODEK, 1996. 384 s.

23. Loseva N.V., Yaroslavtseva I.V. Izmenenie emotsional'nykh perezhivanii u zhenshchin s narusheniem reproduktivnoi funktsii v protsesse psikhologicheskogo konsul'tirovaniya // Problemy teorii i praktiki sovremennoi psikhologii: XII ezhegod. Vseros. (s mezhdunar. uchastiem) nauch.-prakt. konf. studentov, aspirantov i molodykh uchenykh, posvyashch. 20-letiyu fak. psikhologii IGU: tez. dokl. / redkol.: I.A. Konopak i dr. Irkutsk: Izd-vo IGU, 2013. S. 345-348.

24. Makaricheva E.V., Mendelevich V.D. Psikhicheskii infantilizm i neob"yasnimoe besplodie // Sotsial'naya i klinicheskaya psikhiatriya. 1996. № 3. S. 20-22.

25. Men'shikova A.A. Sovladayushchee povedenie beremennykh zhenshchin s onkologicheskimi zabolevaniyami // Psikhologiya i psikhotekhnika. 2011. № 10. S. 42-48.

26. Pavlov I.P. Polnoe sobranie sochinenii: v 6-i t. L.: Izd-vo AN SSSR, 1951. T. 4. 452 s.

27. Rubinshtein S.L. Osnovy obshchei psikhologii. SPb.: Piter, 2000. 528 s.

28. Simonov P.V. Teoriya otrazheniya i psikhofiziologiya emotsii. M.: Tsentr, 1979. $189 \mathrm{s.}$

29. Ukhtomskii A.A. Dominanta. M.; L.: Nauka, 1966. 273 s.

30. Filippova G.G. Psikhologiya materinstva: ucheb. posobie. M.: Izd-vo in-ta psikhoterapii, 2002. $240 \mathrm{~s}$.

31. Filippova G.G. Psikhologiya materinstva. Kontseptual'naya model'. M.: In-t Molodezhi, 1999. 286 s.

32. Yatsenko V.I. Vliyanie defitsita vrozhdennykh dominant lichnosti na povedenie cheloveka // NB: Psikhologiya i psikhotekhnika. 2013. № 10. S. 1-39. (URL: http://www.e-notabene.ru/psp/article_10694.html).

33. Connolly, K.J. Edelmann, R. Cooke. L.D. and Robson, J. The impact of infertility on psychological functioning // Journal of psychosomatic Research. 1992; 36. P. 459-468.

34. Mendola, R., Tennen, H., Affleck, G., McCann, L. Fitzgerald, T. Appraisal and adaptation among women with impaired fertility // Cognitive Therapy and Research. 1990; 14. P. 59-93. 